НОСТАЛЬГИЯ В СИСТЕМЕ БАЗОВЫХ ОППОЗИЦИЙ ДОБРО И ЗЛО В АВТОДОКУМЕНТАЛЬНЫХ ПРОИЗВЕДЕНИЯХ ЛЮДМИЛЫ УЛИЦКОЙ ДЕТСТВО 45-53: А ЗАВТРА БУДЕТ СЧАСТЬЕ И СВЕТЛАНЫ АЛЕКСИЕВИЧ ВРЕМЯ СЕКОНД ХЭНД

NOSTALGIA IN THE SYSTEM OF BASE OPPOSITION OF GOOD AND EVIL IN NON-FICTION BOOKS CHILDHOOD 45-53: THERE WILL BE HAPPINESS TOMORROW BY LYUDMILA ULITSKAYA AND SECONDHAND TIME BY SVETLANA ALEXIEVICH

\title{
LUDMIŁA SZEWCZENKO
}

\begin{abstract}
AвStRact. The vision of the world portrayed in L. Ulitskaya's and S. Alexievich's books is built upon the basic opposition of good and evil. The category of prosthetic memory is juxtaposed with the personal experience of participants and witnesses of the past epoch who tell us about the past. The memories of the lost paradise of the serene years bring about narrators' and responders' nostalgia.
\end{abstract}

Keywords: base opposition, good and evil, prosthetic memory, nostalgia

Ludmiła Szewczenko, Uniwersytet Jana Kochanowskiego w Kielcach, Kielce - Polska, ludaliter@mail.ru

ORCID ID: 0000-0003-3939-2438

Известно, что „ностальгия (от др.-греч.vóoтоs “возвращение на роди-

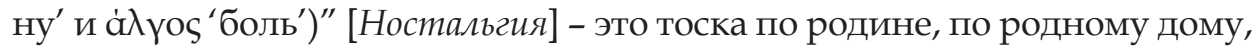
шире - тоска по прошлому, связанная с эмоциональными переживаниями и воспоминаниями о нем. Ностальгия входит в качестве органической составной в так называемую автобиографическую память, которая

трактуется как онтогенетически позднее психологическое новообразование, высшая мнемоническая функция, складывающаяся в совместной опосредствованной знаковыми системами деятельности людей. АП (автобиографическая память - Л. Ш.) организована по смысловому принципу, оперирует с личностно соотнесенным опытом, обеспечивает формирование субъективной истории личного прошлого и переживание себя как уникального, протяженного во времени субъекта жизненного пути [Нуркова 2011: 80].

Как отмечает Евгений Новиков, „ностальгия содержит в себе элемент рефлексии, т. к. подразумевает сравнение прошлого с настоящим (как 
правило, в пользу прошлого), в том числе по этическим основаниям" [Новиков 2009]. Это сравнение невозможно вне базовых оппозиций добро и зло: „нормативно-оценочных категорий, относящихся к социальным явлениям, действиям и мотивам людей, и означающих в обобщенной форме, с одной стороны, должное и нравственно-положительное, а с противоположной - нравственно-отрицательное и осуждаемое" [Добро и зло].

Ностальгия по СССР, или советская ностальгия, это

комплексное социальное явление в России и странах постсоветского пространства, а также в среде русскоязычных граждан дальнего зарубежья, родившихся в СССР, затрагивающее коллективную память об эпохе Советского Союза и связанных с ним деталях [Ностальгия по СССР].

Ностальгия по СССР включает в себя тоску по „развитой социальной системе Советского Союза; симпатии к советской культуре; отношение к целям и задачам СССР как к «великим», «грандиозным» даже у противников режима; положительное отношение к определенным деталям советского быта" [Ностальгия по СССР], к здравоохранению, социальному обеспечению и системе образования, ко всему советскому образу жизни людей, опирающемуся на традиции коллективизма и патернализма, которые осмысляются многими как добро.

Ностальгия по СССР как явление массовое обусловлена, с одной стороны, тоской по ушедшему детству и молодости выросших в советской стране, с другой - ухудшением жизни людей, недовольством их своим положением после распада СССР, идеологическим кризисом, поиском новых и старых ориентиров. Как отмечает Анна Чикишева, уже сама неудовлетворенность реалиями повседневного быта, их несоответствие тому, что было, и идеалам, как и несоответствие новых „веяний” и тенденций сформировавшимся ранее представлениям о добре и должном, приводят к мифологизации прошлого. Исследовательница подчеркивает, что

[...] российская культура предрасположена к социальному мифотворчеству вообще и к ностальгии, в частности. Главным образом это связано с тем, что развитие культуры в России происходило рывками и нередко кардинально меняло свой вектор от эпохи к эпохе. Поскольку существование общества „без прошлого” невозможно, ностальгический миф выступал как аккумулятор значимых норм, ценностей, традиций, которые необходимы для воспроизведения социальных условий жизнедеятельности. России свойственно социально-утопическое проектирование будущего, где утопия выступает формой политического целеполагания, а способом осмысления прошлого является миф [Чикишева 2009].

Анна Чикишева солидаризуется с утверждениями Юрия Левады о том, что 
[...] с момента зарождения в России общественного сознания его доминантой была романтическая концепция „счастливого прошлого”. Формальные истоки этого феномена - идеологическое влияние немецкого романтизма и французских течений периода Реставрации. Реальные же кроются в особенностях российской модернизации, которая сталкивается с сильнейшим внутренним сопротивлением (под лозунгами „остаться собой”, ,"сделать по-своему”, ,"вопреки” и т. п.); это касается не только прямых консерваторов, но почти всех отечественных прогрессистов - от ранних славянофилов и первых народников до большевиков и их державно-реформаторских преемников. Свою лепту в распространение стереотипов ностальгического романтизма внесли утопические социалисты и революционеры, в том числе и марксистские. B XIX - начале XX века практически вся социалистическая критика капитализма [...] ориентировалась на патриархальные или просто архаические (общинные, монастырские и пр.) образцы „домодернизационного” происхождения, по значению своему противостоявшие опасным новшествам" [Чикишева 2009].

Исследовательница справедливо заключает, что нынешняя ностальгия по СССР представляет собой состояние переходного периода, „соединяющее в себе и утопию совершенно особого рода (утопию с обратной проекцией), и она же представляет собой цельный мифообраз, так называемый ностальгический миф - яркий, чувственный, живой" [Чикишева 2009]. Мы же видим его как в передачах и фильмах на всех каналах российского телевидения, так и в проявляющем себя в разных сферах и эксплуатируемом рекламой и новой идеологией так называемом „советском ретро”, в музеях советского быта, появлении ассоциируемого с советской музыкой жанра sovietwave и проч. Обнаруживается он и в разножанровых произведениях как художественной, так и художественно-документальной литературы, в частности, в автодокументальных произведениях, опирающихся на автобиографические воспоминания, личные документы участников и очевидцев происходивших событий.

К примеру, в книге Людмилы Улицкой Детство 45-53: а завтра будет счастье, которую относят к ready-made текстам и к „сентиментальной «литературе факта»” [см. Красовская 2014], собраны воспоминания тех, чье детство пришлось на конец войны и на первые послевоенные годы. Организовав литературный конкурс „После Великой Победы”, писательница получила сотни писем от своих ровесников - россиян, жителей бывших советских республик, а также Израиля, США, Канады, Австрии и Австралии „с воспоминаниями, с простыми словами о жизни, прошедшей в жутком страхе и большой надежде, искренней вере и пламенной любви, уверенности, что «завтра обязательно будет счастье» несмотря ни на что" [Om издательства 2013: 531]. Отобрав те из них (или их фрагменты), которые наиболее ярко, с ее точки зрения, освещали какое-то яв- 
ление, писательница рассортировала их по тематическим главам Ели..., Пили..., Мьлись..,, Одевались.., Играли..., в которых заявленное в названиях содержание было главным объектом рефлексии респондентов, и сосредоточила свое внимание на их самосознании. Помимо упомянутых, в книге имеются главы День Победы, Жизнь двора, Коммуналки и соседи, Животные, Школа, Детдом, Жизнь города, Жизнь деревни, Инвалиды, Про страх, Все умрут, и Сталин тоже..., а также Биографии в письмах, и все это взятое вместе создает мозаичный эффект, позволяющий раскрыть само время, ибо „история - это и быт того времени, это реальная атмосфера, в которой живем мы или в которой жили поколения наших предков" [Дзюба 2008: 29].

Книга Детство 45-53: а завтра будет счастье дает читателям представление о жизни первого послевоенного десятилетия во всем многообразии ее бытовых подробностей и деталей. Каждой из них в их отношении то ли к гастическому (раскрывающему знаковые и коммуникативные функции пищи, напитков в их культурологическом осмыслении), то ли, конечно же, к неосознанно употребляемому респондентами вестиментарному коду (состоящему „из знаков реальной одежды, который направлен непосредственно на конструирование означаемых" [Барт 2003: 45]) как кодам „прочтения” прошлого времени, помимо предметности присуща изобразительная емкость. За счет же производимых Улицкой отбора и сегрегации материала, работающих на его типизацию, а также различных способов его обработки и интерпретации, реалии времени, факты, подробности, упоминаемые респондентами, трансформируются во всей книге в документальные образы. Авторы присланных писательнице автобиографических материалов с любовью вспоминают все те реалии очень убогого послевоенного быта, которые облегчали, а порой и спасали им жизнь в те далекие годы, с особенной теплотой и сердечностью пишут об искренности отношений между людьми, об утраченных ныне взаимовыручке, коллективизме и оптимизме людей того времени, их вере в будущее и умении „радоваться простым радостям" [Улицкая 2013: 199]. Ровесники Улицкой описывают своих родных и близких, друзей и соседей, нелегкий послевоенный быт, школьную жизнь, игры и жизнь двора, причем большинство из этих воспоминаний „написаны с нежностью и ностальгией” [Улицкая 2013: 162]. Реже в их письмах встречаются воспоминания о проявлениях несправедливости, подозрительности и жестокости по отношению к военнопленным, калекам и детям-сиротам - воспоминания, заставляющие Улицкую думать, что „...сидят где-то в глубинах человеческой натуры потенциалы разные, добро и зло ведут свою борьбу именно на этом персональном уровне" [Улицкая 2013: 7]. 
Конечно же, все, о чем написали Улицкой ее респонденты, содержит в себе ностальгию, прежде всего, по детству и юности, по годам, когда многого из того, что тогда совершалось в стране они, будучи малолетками, просто не видели или не понимали. К тому же их память о прошлом отягощена тем, что уже на нее „наложилось” со временем под влиянием пропаганды. То есть в их воспоминаниях мы видим то, что Элисон Ландсберг назвала prosthetic memory - памятью протезированной. Как отмечает Марина Балина, эта память базируется не только на личных, пережитых воспоминаниях, но и на

смеси широко доступных и распространяемых средствами массовой информации фактов, легенд, мифов. [...] Весь этот сплав прочитанного, пережитого, услышанного поступает в „личный архив"... и интенсивно переживается... формируя отношение к реальности [Балина 2003].

И здесь важную роль начинает играть слово автора-составителя книги этих воспоминаний - Улицкой, с одной стороны, акцентирующей аутентичность, правдивость и ценность всех представляемых ею свидетельств, с другой, - осмысляющей их с точки зрения своего опыта тех же лет и с позиции внутренне противоречивого времени составления текста всей книги, одновременно и продолжающей культивировать миф о советской стране, и его разоблачающей, разрушающей. Взгляд на прошлое Улицкой, также выступающей в произведении как свидетель эпохи, шире, чем у ее респондентов, к тому же условием конкурса ограничивших воспоминания лишь периодом своего созревания. Неслучайно она замечает, что за ностальгией по детству в упоминаемых ими вскользь фактах и подробностях ей видны все те ужасы, что пережило ее поколение. Неслучайно уже в предисловии к книге она пишет:

Сложенные вместе, отрывки из писем людей разного возраста, социального происхождения и образовательного уровня меняют отношение к событиям прошлого, расставляют акценты иные, чем те, к которым мы давно привыкли. Они показывают изнанку советского мифа, правду жизни маленького человека, которому дана одна-единственная жизнь во времени, „которого не выбирают”... [Улицкая 2013: 6].

Каждую из глав книги Детство 45-53: а завтра будет счастье предваряют рассуждения самой Улицкой о прошлом и настоящем, ее раздумья философско-этического содержания и личные воспоминания, представляющие ее как ровесника и свидетеля той же эпохи. В этих предисловиях к главам писательница размышляет о том, как формировалась этика ее поколения, проявляющаяся в связях между людьми, в отношении к близким, к соседям, к вещам и пище, как менялись со временем пред- 
ставления о своих и врагах, об „отце народов” , военнопленных и заключенных, причем большинство этих размышлений дополнены экскурсами в историю, данными официальной и неофициальной статистики, документами и отсылками к разным российским и зарубежным архивным источникам, трудам социологов и психологов, что, в свою очередь, служит коррекции тех неточностей и ошибок, которые неизбежны при ностальгических воспоминаниях. Особенной же остротой отличаются рассуждения Улицкой о русской ментальности, русском национальном характере, противоречиях русской истории и русской мысли касательно добра и зла, их трактовок и восприятия разными представителями ее поколения в разные десятилетия. По своей сути все эти раздумья писательницы являются своего рода моральной рефлексией над автобиографической ностальгией ее респондентов, и их значение неоценимо. Как справедливо отмечает Евгений Новиков,

именно с помощью такой рефлексии можно обнаружить слабые стороны ностальгии (например, неоправданную идеализацию некоторых аспектов прошлого) и игнорировать полученную в результате нее реконструкцию прошлого, зная, что она ошибочна. Именно при такой рефлексии над ностальгией оказывается не просто возможным, но и необходимым сосуществование „светлой тоски” по одним эпизодам прошлого и раскаяния в других [Новиков 2009].

И именно эта рефлексия организует само восприятие всех представленных в книге Детство 45-53: а завтра будет счастье воспоминаний в параметрах базовых оппозиций добро и зло.

К автодокументальным произведениям, осмысляющим ностальгию по СССР, можно отнести также книгу Время секонд хэнд, представляющую собой расшифровки магнитофонных записей интервью и бесед Светланы Алексиевич с участниками и свидетелями реальных событий, связанных с историей СССР 20., 30., военных и послевоенных годов, с периодами хрущевской „оттепели”, застоя и перестройки, с „бандитскими” девяностыми и современностью. Петр Вайль определяет ее жанр как „oral history - устная история” [Вайль 2008]. Этот термин на Западе широко распространен в профессиональном словаре историков, а также в культурологии и журналистской документалистике. Его появление связано с использованием новых технических средств, благодаря которым „устная история” обрела статус полноценного исторического источника и „возродила древнейший метод исторического исследования" [Хубова 1992]. Отметим, что этот же метод для сбора устных воспоминаний использует и Алексиевич, однако ее подход к материалу отличен от практикуемого культурологами и историками, а также теми западными журналистами-документалистами, которые 
работают в рамках широкого антиэстетического движения и противостоят своим творчеством миру художественному, его десакрализируя и обнажая. Отличен он и от того, что являет читателям документалистика эпохи постмодернизма в целом, которой, как пишет Елизавета Манскова, присущи

плюрализм мнений и общая десакрализация, уход из „вертикали” в „горизонталь” (внимание к культуре повседневности и быту вместо бытия), отрицание фундаментальных культурных оппозиций „высокое - низкое”, моральное - аморальное [Манскова 2011].

В книге Время секонд хэнд все события, связанные как с жизнью в СССР, так и на постсоветском пространстве, действительно предстают в их обыденном, будничном измерении, раскрывающем время в параметрах жизни обычного человека. В произведении даны разные представления о событиях, ибо писательнице „хотелось, чтобы каждый прокричал свою правду”, и у нее „все говорят - и палачи, и жертвы" [Игрунова 2016: 498]. Светлана Алексиевич демонстрирует разные впечатления и эмоции своих соотечественников в связи с настоящим и прошлым, показывает варианты носящихся в их умах идей и воспоминаний об СССР в координатах ими же понимаемых добра и зла. Часто не совпадая друг с другом и с тем, как их трактует писательница, они вступают в диалогические отношения не только между собой, но и с ее авторским словом, образуя многоголосый хорал. Причем все его голоса, в них представленные во всем единстве для читателя, выступают „не как «сама реальность», а как ее идеальная конструкция, «как модель», активно соотносимая с оригиналом" [Дзюба 2008: 29]. Писательница все ими сказанное, „пропетое” уже отобрала, систематизировала, обращаясь как к тематическому и хронологическому, так и к повествовательному монтажу, выстроила в соответствии с логикой и движением своей мысли, дополнила документами и фактическим материалом, снабдила отдельными комментариями и ремарками, подкрепив в конце книги своими суждениями как носителя замысла произведения в его идейном и образном воплощении. То есть в книге фундаментальные оппозиции добро и зло, моральное - аморальное, высокое - низкое, прекрасное и безобразное, несмотря на представленный калейдоскоп их трактовок, четко определены. Сам же материал, благодаря бережному к нему отношению Алексиевич, сохраняет свое аутентичное и сакральное содержание и дополняется привносимым в него как художественным, так и эстетическим компонентом.

В книге Алексиевич представлена ностальгия по разным периодам жизни СССР и годам постсоветского времени. В устных рассказах и в ин- 
тервью ее собеседников фигурируют революция, коллективизация и индустриализация, голодомор и репрессии, культ личности Сталина, героизм и трагизм бытия человека в военное время и послевоенные годы; иллюзии „оттепели” и преследование свободомыслия в брежневские времена, вера в лучшую жизнь в горбачевский период и крушение всех надежд в девяностые; распад страны, обострение межнациональных и межконфессиональных конфликтов; обнищание населения и утрата иллюзий касательно нового жизнеустройства, персональная и социальная ностальгия по прошлому и ее усиление в веке нынешнем. Одни из тех, кто „намертво прирос к идее, впустил ее в себя так, что не отодрать - государство стало их космосом, заменило им все, даже собственную жизнь" [Алексиевич 2016: 8], с ностальгией рассказывают о жизни в СССР и трактуют все, с нею связанное, как добро; другие же, выросшие на „самиздате” и „тамиздате”, в ней видят зло, вспоминают с восторгом то „ощущение праздника” [Алексиевич 2016: 231], что сопутствовало перестройке; третьи мечтают о такой идее для русских людей, „от которой мороз по коже и мурашки по позвоночнику" [Алексиевич 2016: 199]: „Русскому человеку надо во что-то верить... Верить в светлое, возвышенное”, ибо у него „в подкорке заложена империя и коммунизм” [Алексиевич 2016: 38]. Причем все, что и как они вспоминают, для них еще живо, и это подтверждает мысль Мартина Хайдеггера, что „прошлое - это не то, что осталось позади, чего уже больше нет, а то, что постоянно присутствует и определяет собою как настоящее, так и будущее" [Хайдеггер 1998: 337]. Вывод же самой писательницы однозначен: социализм закончился, но на смену ему желаемое не пришло:

Потому что все идеи, слова - все с чужого плеча, как будто вчерашнее, ношенное. Никто не знает, как должно быть, что нам поможет, и все пользуются тем, что знали когда-то, что было прожито кем-то, прежним опытом. Пока, к сожалению, время секонд хэнд [Игрунова 2016: 503].

Как видим, в опирающихся на автобиографические воспоминания и личный документ книгах Людмилы Улицкой Детство 45-53: a завтра будет счастье и Светланы Алексиевич Время секонд хэнд ностальгия по СССР россиян заявлена во всей вариативности и широте. Причем в обоих случаях существенную роль в ее осмыслении играет по-разному актуализированная в пространстве произведений и организующая восприятие всех материалов рефлексия автора, выводы, к которым „подводят" читателей обе писательницы, размышляя о времени и о сути добра и зла. 


\section{Библиография}

Алексиевич С. 2016. Время секонд хэнд, Москва: Время.

Балина М. 2003. Литература non fiction, [в:] А. Абрамов, М. Айзенберг, М. Балина, С. Гандлевский, Л. Гудков, И. Клех, О. Либкин, С. Лурье, Н. Работнов, А. Чудаков, Литература пon fiction, „Знамя”, № 1, электронный ресурс: http:/ / magazines. russ.ru/znamia/2003/1/rl.html (доступ 7.06.2017).

Барт Р. 2003. Система Моды. Статьи по семиотике культуры, пер. с франц., вступ. слово и составление С. Зенкина, Москва: Изд-во им. Сабашниковых.

Вайль П. 2008. История устная и частная, Радио Свобода 31.05.2008, электронный pecypc: www.swoboda.org/a/449920.html (доступ 21.06.2017).

Дзюба I. 2008. Спогади і роздуми на фрінішній прямій, Київ: Криниця.

Добро и зло. Электронный ресурс: https:/ / ru.wikipedia.org./wiki/Добро_и_зло (доступ 10.07.2017).

Игрунова Н. С. 2016. „Социализм кончился. А мы остались”. Беседа со Светланой Алексиевич, [в:] С. Алексиевич, Время секонд хэнд, Москва: Время.

Красовская С. 2014. Переиздание как фермент литературной эволюиии: Андрей Сергеев. Omnibus. Роман, рассказы, воспоминания, стихи, „Знамя”, № 4, электронный ресурс: http:/ / magazines.russ.ru/znamia/2014/4/27k.html (доступ 2.10.2018).

Левада Ю. А. 2002, „Человек ностальгический”: реалии и проблемы, „Мониторинг общественного мнения: экономические и социальные перемены", № 6 (62).

Манскова Е. А. 2011. Современная российская теледокументалистика: динамика жанров и средств экранной выразительности, автореферат диссертации на соискание ученой степени кандидата филологических наук, Екатеринбург: ЕГУ, электронный ресурс: http://elar.urfu.ru/bitstream/10995/3561/3/urgu085s.pdf (доступ 30.06.2017).

Новиков Е. В. 2009. Нравственный смысл ностальгии, диссертация на соискание ученой степени кандидата философских наук, Москва: МГУ, электронный ресурс: www.dissert.com/content/nravstvennyj-smysl-nostalgii (доступ 7.06.2017).

Ностальгия. Электронный ресурс: https://ru.wikipedia.org./wiki/Ностальгия (доступ 10.07.2017).

Ностальгия по СССР.Электронный ресурс: https:/ / ru.wikipedia.org./ wiki/Ностальгия по СССР (доступ 10.07.2017).

Нуркова В. В. 2011. Автобиографическая память с прозиций культурно-деятельной психологии: результаты и перспективы исследования, „Вестник Московского университета. Психология", серия 14, № 1, электронный ресурс: www.mspsyj.ru/pdf/ vestnik_2011_1/vestnik_2011-79-90.Pdf (доступ 7.06.2017).

От издательства. 2013, [в:] Л. Улицкая, Детство 45-53: а завтра будет счастье, Москва: ACT.

Светлана Алексиевич. Электронный ресурс: http://www.litportal.ru.all/author5481 /about.html (доступ 7.06.2017).

Сивакова Н. А. 2014. Цикл Светланы Алексиевич "Голоса Утопии”: особенности жанровой модели, „Известия Гомельского гос. Ун-та им. Ф. Скорины”, № 1 (82), электронный pecypc: repo.gsu.by/bitstream/123456789/1118/1/35\%20Сивакова\%2848-151\%29. pdf (доступ 7.06.2017).

Улицкая Л. 2013. Детство 45-53: а завтра будет счастье, Москва: АСТ. 
Хайдеггер М. 1998. Пролегомены к истории понятия времени, пер. с немецкого Е. В. Борисова, Томск: Водолей.

Хубова Д. Н. 1992. Устная история и архивы: зарубежные концепции и опыт, автореферат диссертации на соискание ученой степени кандидата исторических наук, Москва: РГУ, электронный ресурс: cheloveknauka.com/ustnaya-istoriya-i-arhivy-zarubezhnye-konseptsii-i-opyt (доступ 1.05.2017).

Чикишева А. С. 2009. Феномен ностальгии в постсоветской массовой культуре, [в:] Л. Спивак (ред.), Фундаментальные проблемы культурологии: Сб. ст. по материалам конгресса, Москва: Новый хронограф: Эйдос, т. 6, электронный ресурс: http:/ / ес-dejavu.ru/n/Nostalgia.html (доступ 7.06.2017). 